\title{
Antecedents of Blackboard Adoption by Lecturers at a South African Higher Education Institution - Extending GETAMEL
}

\author{
https://doi.org/10.3991/ijet.v16i01.16821 \\ Obert Matarirano ${ }^{(区)}$, Nobert R Jere \\ Walter Sisulu University, East London, South Africa \\ omatarirano@wsu.ac.za \\ Hlanganani S Sibanda, Manoj Panicker \\ Walter Sisulu University, Butterworth, South Africa
}

\begin{abstract}
Learning Management Systems (LMS) have become central to the teaching and learning in Higher Education Institutions (HEIs). Despite several benefits identified in literature, the utilisation of LMS, especially in African countries' context, has remained low. The aim of this paper was to examine the effects of pre-identified factors on adoption of Blackboard LMS by lecturers at a selected HEI in South Africa, guided by an extended General Extended Technology Acceptance Model for E-Learning (GETAMEL). The study considered responses from lecturers who utilise the Blackboard LMS. A cross sectional electronic survey was carried out to obtain data from 101 lecturers, who were conveniently sampled to express their perceptions on the LMS. Structural equation modelling, utilising SmartPLS3, was used to analyse the collected data The results confirmed that behavioural intention (BI) influenced actual use whilst BI in turn, was influenced by perceived usefulness (PU) and subjective norm (SN). Attitude was influenced by PU but had no significant effect on BI The external factors that influenced perceived ease of use (PEOU) included perceived enjoyment (ENJOY), system self-efficacy (SE), and system anxiety (ANX) whilst PU was influenced by job relevance (JR) and PEOU. University management at the HEI under study should consider the determinants of SE, ENJOY and ANX if they are to improve adoption and utilisation of Blackboard by lecturers. The study findings imply that a LMS that is adopted and used, is one that is considered useful, otherwise users will be reluctant to use it. The findings can assist HEIs in preparing their lecturers before adopting e-learning systems, such as training and technical support, thus, enhancing LMS adoption and utilisation. This study contributes to the body of knowledge on factors influencing LMS adoption and use. In addition, it establishes the applicability of GETAMEL in a South African university context.
\end{abstract}

Keywords-Technology acceptance, learning management systems, Blackboard, higher education institution 


\section{Introduction}

Information and Communication Technology (ICT) has become an integral part of human activity in social, economic, industrial enterprises and education. In education, ICT significantly affects learning experiences of university students [1]. With the majority of university students being 'digital natives', the use of technology has become one of the key solutions to learning and teaching challenges [2], [3]. The popularity of technology in teaching and learning is witnessed even at pre-primary schools for teaching young children [4]. One key ICT frequently used in education is a Learning Management System (LMS). Implementation of LMS to enhance flexibility in teaching and learning in Higher Education Institutions (HEI) has become part of the strategic plan [5] and as such, considerable investments in such systems has been made. Researchers have supported the use of LMS and reported some benefits as well as challenges associated with its utilisation [6]-[8].

Despite the well documented benefits of ICT usage in education, there is low utilisation in teaching and learning and numerous factors have been identified as reasons behind the low utilisation [9], [10]. Among the factors cited for reluctance in adopting e-learning systems include inappropriate deployment of relevant ICT equipment, inadequate training at all levels and absence of basic conditions for the development of educational content [11].

Whilst a number of studies were carried out on e-learning in HEIs around the world, very few were carried out in South Africa and Sub Saharan Africa. Most studies available are carried out in Asian countries [12], [13]. In a meta-analysis of studies on factors affecting perceived usefulness and perceived ease of use of e-learning technologies, Baki, Birgoren and Aktepe [12] found only 6 studies from Sub Saharan Africa. A search of EBSCO Discovery Service by Granić and Marangunić [13] resulted in only one empirical, peer reviewed journal article that primarily used Technology Acceptance Model (TAM) and its different versions on education in South Africa.

Another limitation of the available studies in literature is the primary focus on elearning adoption by university students. Very few studies considered lecturers or any other group of people [14], leading to a suggestion by Granić and Marangunić [13] to include academic staff in future studies, who form an integral part to the learning process. There is very little research in South Africa that focuses on the LMS adoption by lecturers at HEIs.

South African higher education system is characterised by two sets of institutions; historically advantaged institutions (HAIs) and historically disadvantaged institutions (HDIs) [15]. Most HDIs are in a state of under-development and financial distress compared to HAIs. The under-development has prevented HDIs from successfully fulfilling their missions and establishing themselves as vibrant academic enterprises [16]. On the contrary, HAIs benefitted from favourable policies and resource allocation that gave them an edge in productivity and competitiveness [17]. The selected HEI is an HDI, which adopted the Blackboard LMS in 2009 academic year. There is evidence, based on the statistics of LMS usage, that the LMS has not yet fully been utilised as the institution intended. Despite paying for substantial annual licence fees, the adoption and utilisation of Blackboard by lecturers and students is still low. Ac- 
cording to the 2019 LMS access logs, as shown in Table 1, 32716 students were enrolled in the 2018 academic year yet only 5970 active students and slightly over 1100 instructors and leader users accessed the system.

It is against this backdrop that a survey on antecedents for adoption of Blackboard LMS by lecturers, guided by a model, was conducted. The paper utilised the General Extended Technology Acceptance Model for e-Learning (GETAMEL) as the primary framework. In addition to GETAMEL, job relevance identified in TAM2 and system accessibility and technical support identified in TAM3, were used. The paper addressed the following research question: What are the factors that influence the adoption and use of Blackboard LMS by lecturers at the selected HEI in South Africa? The primary objective of the paper was to analyse the factors that affect LMS adoption by lecturers guided by GETAMEL. The secondary objectives were to:

- Examine factors that influence lecturers perceived ease of use and perceived usefulness of the LMS.

- Examine the factors that influence attitude towards use, behavioural intention to use LMS and LMS actual use.

\subsection{Selected HEI background}

The selected HEI is located in one of South Africa's most rural provinces. The institution was a product of a merger of three institutions in 2005. The merged institution has four campuses, located in four geographically dispersed areas where a number of similar qualifications are offered. In 2009, the institution adopted the Blackboard LMS to enable e-learning. Unfortunately, the adoption of the LMS was poor. Muuro, Wagacha, Oboko and Kihoro [18] claim that there exists a lack of awareness in universities prior to the introduction of LMSs. Their study found that little preparatory work is done to create awareness to instructors who carry out lectures using the LMS. This lead to underutilisation of the LMSs. According to Coleman and Mtshazi [19], some universities strictly require their lecturers to actively engage in research work, taking no consideration of the time required to learn use of the LMSs. Some lecturers become frustrated when they are also expected to learn use of LMS in addition to research work, activities they find time consuming. In 2014, as shown in Table 1 , the usage of LMS at the selected HEI was basically zero as shown by the number of active courses which was zero. Table 1 shows that the highest usage of LMS over the period was 9010 views per day. This was against an enrolment count of $32319 \mathrm{im}-$ plying an overall utilisation rate of less than $30 \%$. The number of instructors utilising the system is also low if the total number of employees, both academic and support, is to be considered. The evidence in Table 1 demonstrates the need to discover reasons behind low utilisation, which may in turn, improve adoption and usage of the LMS within the institution. 
Table 1. LMS usage at the selected HEI between 2014 and 2018

\begin{tabular}{|l|c|c|c|c|c|}
\hline & $\mathbf{2 0 1 4}$ & $\mathbf{2 0 1 5}$ & $\mathbf{2 0 1 6}$ & $\mathbf{2 0 1 7}$ & $\mathbf{2 0 1 8}$ \\
\hline Number of active courses & 0 & 191 & 985 & 632 & 1779 \\
\hline Number of active users & 304 & 569 & 3369 & 1414 & 5970 \\
\hline Number of instructor/leader users & 217 & 683 & 590 & 736 & 1122 \\
\hline Average page views per day & 1958 & 3420 & 4432 & 7507 & 9010 \\
\hline Enrolment head count & 24395 & 26353 & 28885 & 30814 & 32319 \\
\hline
\end{tabular}

The rest of the paper is structured as follows: literature review, methodology used, results, discussion and conclusion.

\section{$2 \quad$ Literature Review}

In relation to the purpose of the study, which is to examine the effects of external factors identified in GETAMEL as well as job relevance, system accessibility and technical support on adoption of a LMS at the selected HEI, this section reviews literature related to the meaning of LMS, the challenges that HEIs in South Africa encounter in utilising LMSs, LMS adoption models and factors influencing LMS adoption. This discussion culminates with formulation of hypotheses.

A Learning Management System is an online program that serves as a learning and communication platform for students [20]. Blackboard is one of the frequently researched LMSs as evidenced by a basic search on Web of Science Collection, which results in Blackboard as one of the commonly mentioned LMSs, alongside Moodle. Blackboard is an online LMS designed to enhance teaching and learning efforts [21]. It has potential to motivate students' participation, embrace multiple intelligences and enhance students' academic performance [22]. Despite the identified benefits of LMSs in HEIs, BB utilisation among academic staff has been poor [9]. The challenges facing HEIs in adopting e-learning platforms are diverse and complex [3], [10]. According to Bentley, Tinney and Chia (2005), as cited in [23], some challenges of elearning include language, educational culture, technical infrastructure, learning style, reasoning patterns, and cultural and social context whilst [14], [24] identified varying learner academic preparedness, large classes, language issues, inadequate curriculum design, diverse background; and academic ability as reasons behind underutilisation.

\subsection{Challenges faced in implementation of LMSs in South Africa's HEIs}

More than two decades after the transition from apartheid to democracy, South Africa remains a very unequal society, based on race, class, gender and socio-economic status [25]. This historical background, which is characterized by socio-economic inequalities and extreme levels of poverty, makes implementation of LMS more difficult for some HEIs. In addition, insufficient technical support, low network capacity, poor coordination and resistance to change pose challenges to e-learning adoption [26].

To remain relevant and accommodate the growing demands of modernisation, HEIs need to optimise the use of suitable digital technology, collaborate and share 
infrastructure, promote open educational resources (OER) and the sharing of materials and resources and develop staff capacity in the use of ICT [27]. Challenges encountered by HEIs differ from one institution to the other, but the commonly cited in literature, as highlighted by [17], [23], [25] include:

- Low motivation to adopt new technology;

- Lack of technical support from the institutions;

- Poor ICT support infrastructure affecting internet access and networking in HEI;

- Lack of time by the instructors to guide the students on how to use LMSs;

- Heavy workloads;

- Underutilisation of available functionalities;

- Lack of business continuity plans to address pandemics such as COVID-19 by HEIs.

The study is based on one selected HDI in South Africa. The identified problem is that HDIs as well as other educational organisations in South Africa, are still in the early stages of trying to motivate lecturers and students to accept, adopt and use elearning platforms.

\subsection{LMS adoption models}

Although technology improves efficiency of teaching and learning in HEIs, the success of LMSs is greatly reliant on the acceptance of stakeholders to adopt technology in the education curricular. Lucas [28] reports that one of the biggest threats to the adoption of new technology is resistance of university faculty who feel that systems which have been in place for a long time in institutions should be preserved.

Most of the factors affecting adoption and use of technology are established through the technology acceptance models. A number of theories have been established, with Technology Acceptance Model (TAM) being the most frequently used theory. TAM, established by Davies in 1986, argues that perceived usefulness of technology (PU) and perceived ease of use of technology (PEOU) affect the attitude towards use (ATT) which influences behavioural intention to use the technology (BI). $\mathrm{BI}$ is considered to be the ultimate driver of technology use (USE). In addition to ATT, PU is also claimed to influence BI. The PU and PEOU that influence ATT and $\mathrm{BI}$ are in turn, influenced by other external factors [29]. The common external factors that influence PEOU and PU were established by Abdullah and Ward [30] through GETAMEL.

\subsection{Theoretical research basis (GETAMEL)}

GETAMEL has its theoretical background in TAM. It was established to include common external factors that influenced PEOU and PU. The external factors that were confirmed to have an impact on PEOU included subjective norm (SN), experience (EXP), self-efficacy (SE), enjoyment (ENJOY) and anxiety (ANX) whilst PU was affected by SN, EXP, ENJOY and SE [30]. The definitions of the identified external factors are provided in Table 2. 
Table 2. Definitions of external factors in GETAMEL

\begin{tabular}{|c|l|}
\hline Factor & \multicolumn{1}{c|}{ Definition } \\
\hline Subjective norm & $\begin{array}{l}\text { It is the user's perception of the social influence to utilise ICT based on culture and } \\
\text { norms [31]. }\end{array}$ \\
\hline Experience & $\begin{array}{l}\text { Refers to the comfort level attained in using computer programs and other applica- } \\
\text { tions that are associated with computers [32]. }\end{array}$ \\
\hline Self-efficacy & $\begin{array}{l}\text { It is the user's perceived competence to utilise obtained skills to engage ICT systems } \\
\text { successfully [31]. }\end{array}$ \\
\hline Perceived enjoyment & $\begin{array}{l}\text { Refers to the extent to which the utilisation of ICT is regarded to be enjoyable in its } \\
\text { own right [31]. }\end{array}$ \\
\hline Anxiety & It is the state of uneasiness related to use of ICT [31]. \\
\hline
\end{tabular}

GETAMEL is graphically presented in Figure 1.

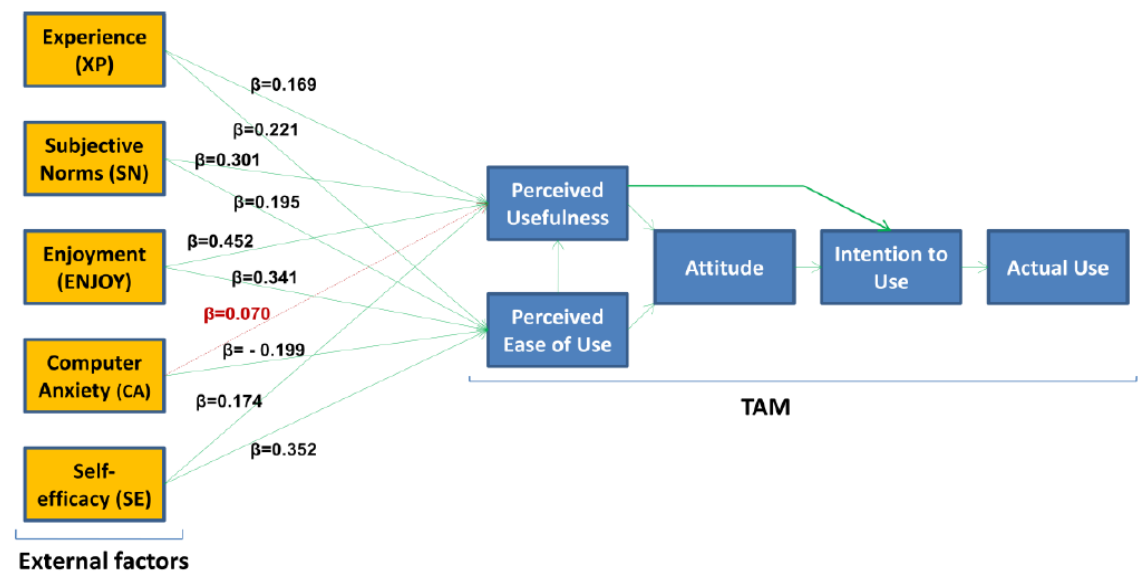

Fig. 1. GETAMEL (Abdullah and Ward, 2016)

GETAMEL has been successfully used in several studies since its inception [31]. The credibility of external variables established in GETAMEL was validated in metaanalysis studies such as by [12] and empirical studies by [33]-[36].

\subsection{Extensions to GETAMEL}

For the current study, GETAMEL was extended with some external factors confirmed in TAM2 and TAM3 to be significant drivers of technology acceptance [37], [38]. These factors included job relevance from TAM2, system accessibility and technical support from TAM3. Job relevance, which is equated to system compatibility in other studies, was considered to have a direct effect on PU. It is defined as the users' perception on how the system is applicable to their job [37]. Job relevance represents the degree to which a user perceives technology as being consistent with the existing values, needs, and experiences of potential users [39].

TAM3 added facilitating conditions, referred to as perceptions of external control, to the list of external factors that influence PEOU. Facilitating conditions are related 
to the control beliefs of users that organisational resources and support structure are available to enable use of a system [40]. Considering the resource limitations of HDIs in South Africa, it was deemed necessary to include this group of factors to the study. The facilitating conditions considered included BB accessibility (ACC) and institutional technical support (TS). Accessibility refer to the degree to which a user perceives that opportunity and access to a system are present [31]. Technical support refers to the provision of information and understanding about a technology to the user. This support can be provided through helpdesk, online or departments of ICT [41].

\subsection{Antecedents of LMS adoption and usage}

Antecedents of PEOU and PU: Several studies that conducted to establish factors that affect PEOU and PU. A study by Abdullah and Ward [30], which resulted in GETAMEL, is one such study which found SN, EXP, SE, ENJOY and ANX to affect PEOU whilst SN, EXP, SE, ENJOY and PEOU where drivers for PU. All these factors exerted a positive influence on PEOU and PU except for ANX which had a significant negative influence. These factors were tested in several empirical studies which validated the findings. These include PEOU being positively influenced by subjective norm [34], [42], experience [35], [43], self-efficacy [44], [45], perceived enjoyment [34], [45] whilst being negatively influenced by anxiety [42], [46]. Perceived usefulness was positively influenced by subjective norm [47], [48], experience [33], [35], self-efficacy [9], [35], enjoyment [34], [44] and perceived ease of use [42], [48].

In addition to factors established in GETAMEL, job relevance positively influences PU [49], [50] whilst system accessibility [36] and technical support have significant effects on the perceived ease of use of LMS [41], [51], [52].

This led to the following hypotheses related to external factors affecting PEOU and PU being formulated:

H1: SN has a positive influence on PEOU

H2: EXP has a positive influence on PEOU

H3: SE has a positive influence on PEOU

H4: ENJOY has a positive influence on PEOU

H5: ANX has a negative influence on PEOU

H6: ACC has a positive influence on PEOU

H7: TS has a positive influence on PEOU

H8: $\mathrm{SN}$ has a positive influence on $\mathrm{PU}$

H9: EXP has a positive influence on PU

H10: SE has a positive influence on PU

H11: ENJOY has a positive influence on PU

H12: PEOU has a positive influence on PU

H13: JR has a positive influence on PU

Antecedents of Attitude: Both GETAMEL and the original TAM collude that ATT is influenced by perceived usefulness and perceived ease of use of technology. Most empirical studies also found these two factors to have a significant effect on 
attitude towards use of technology. PU [36], [53] and PEOU [34], [35] were found to strongly influence ATT. The following hypotheses were suggested as a result.

H14: PEOU has a positive influence on ATT

H15: PU has a positive influence on ATT

Antecedents of Behavioural Intention: The original TAM model and GETAMEL agree on PU and ATT as variables that influence behavioural intention to use technology. Whilst maintaining the significance of PU on BI, a number of technology acceptance theories such as Acceptance and Satisfaction Model for E-learning [12], Unified Theory of Acceptance and Use of Technology (UTAUT) [40], TAM2 [37] and TAM3 [38] considered attitude not to affect acceptance of technology. Some meta-analysis and empirical studies, however, argue that attitude directly influence behavioural intention to use technology. Dwivedi et al. [54] in a meta-analysis and structural equation modelling study found attitude to have a central role in acceptance and use of technological innovations. Attitude was found to have a direct effect on behavioural intention and use behaviour, implying that it partially mediated the effects of PEOU and PU [54]. In addition to PU and ATT influencing BI, SN [37], [38], [40] and PEOU [12], [37], [38], [40] are also considered to have an influence on BI to use technology.

Several empirical studies confirmed the positive influence of the identified variables on BI. These include [36], [55] on PU, [34], [50] on ATT, [56], [57] on SN and [46], [58] on PEOU. Based on the discussion above, the following hypotheses were suggested:

H16: PEOU has a positive influence on BI

H17: PU has a positive influence on BI

H18: SN has a positive influence on BI

H19: ATT has a positive influence on BI

Antecedents of Use Behaviour: Most empirical studies, just like most models of technology acceptance, find BI to be the most influential driver of technology use. People who intend to use technology end up using it [55], [58]. The following hypothesis was therefore formulated:

H20: BI has a positive influence on USE

The relationships between the different variables identified for the study (conceptual framework) are summarised in Figure 2. The solid arrows portray the GETAMEL, whilst the dotted arrows depict the extensions to the model. 


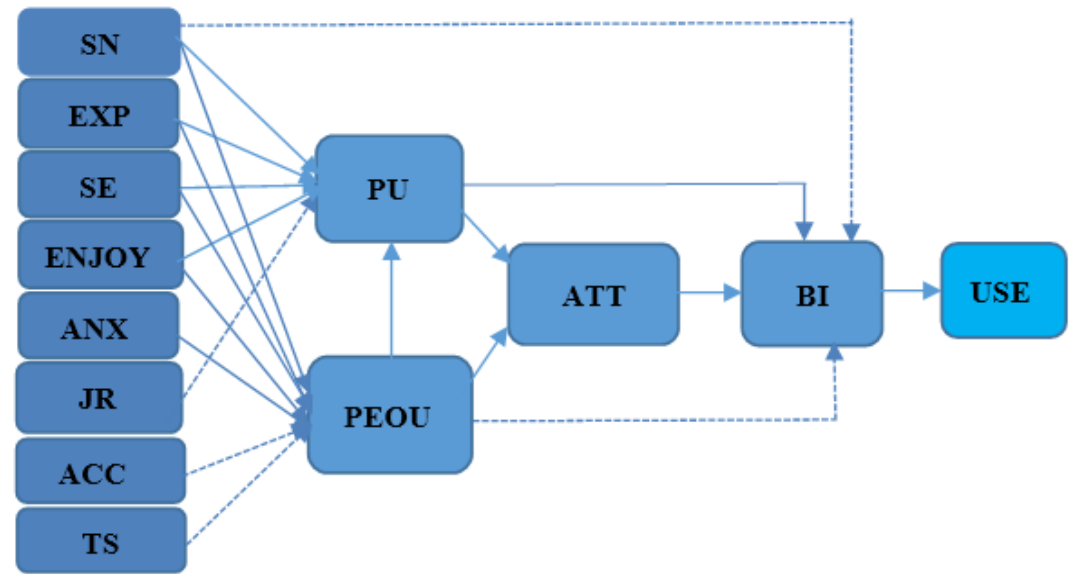

Fig. 2. Conceptual Framework

\section{Methodological Approach}

\subsection{Population and sampling}

The target population for the study is the HEI lecturers utilising LMS in their teaching at the selected institution. The targeted institution, according to its website, has over 1800 academic employees. However, not all academic staff members make use of the LMS in carrying out their teaching responsibilities. The study targeted lecturers who were using the LMS. A convenience sampling method was used to select respondents.

\subsection{Data collection instrument}

A survey was used to obtain data, utilising a self-administered questionnaire. The questionnaire was developed with guidance from the extended GETAMEL. It had 5 sections with items representing dependent variables such as perceived ease of use, perceived usefulness, attitude to use, behavioural intention to use technology, actual use and independent variables that included subject norm, system experience, selfefficacy, system enjoyment, system anxiety, job relevance, system accessibility and technical assistance. The first section described the demographics of the respondents whilst the section 2 solicited LMS usage information, with two items. Section 3 included 29 items representing system enjoyment, job relevance, perceived ease of use, perceived usefulness, attitude towards LMS use and behavioural intention to use the LMS. Section 4 had 12 items covering self-efficacy, system anxiety and system experience whilst section 5 comprised 12 items covering subjective norm, system accessibility and technical support. Items from sections 3 to 5 were answered by using a five-point Likert scale where 1 indicated strongly disagree and 5 represented strongly agree. To improve reliability and validity of the research instrument, questions 
from prior studies such as [59], [60] were adapted. In addition, reliability was ensured by pretesting the questionnaire to 15 academic staff members.

\subsection{Data collection}

A hyperlink to the questionnaire was shared with lecturers via academic departmental WhatsApp Group platforms in the first two weeks May of 2020. Participation in the study was voluntary and participants remained anonymous. During the survey, ethical considerations were observed, and respondents were notified that the study was not related to any contracts they had with the institution. A total of 116 responses were received, but 15 were received from a pre-test, and thus were not used for final data analysis, leaving 101 responses being used for data analysis. The composition of the respondents who participated in the survey and used for analysis is presented in Table 3 .

Table 3. Composition of respondents

\begin{tabular}{|l|c|c|c|c|}
\hline \multicolumn{1}{|c|}{ Age } & Female & Male & Prefer not to say & Total \\
\hline 30 years or less & 1 & 6 & & 7 \\
\hline Between 30 and 40 years & 15 & 27 & & 42 \\
\hline Between 40 and 50 years & 14 & 13 & & 27 \\
\hline Between 50 and 60 years & 8 & 6 & & 14 \\
\hline 60 years or above & 1 & 8 & & 9 \\
\hline Not indicated & & & & 2 \\
\hline Total & 39 & 60 & 2 & 101 \\
\hline
\end{tabular}

Of the 101 respondents, 60 were male lecturers whilst the remaining 39 were female. Two respondents neither indicated their gender nor the age. The modal age class was 30 to 40 years whilst almost half of the respondents were below the age of 40. Most of the respondents were aged between 30 and 50 years, which comprised about $70 \%$ of respondents who indicated their age.

\subsection{Data analysis}

The data, which was collected using google forms, was presented in MS Excel and analysed by structural equation modelling (SEM) utilising SmartPLS data analysis software [61]. SEM is the often used type of data analysis method used in the technology acceptance studies [13]. SEM was used to establish the relationships between variables as well as checking the statistical significance of the relationships. SEM is an analytical tool that estimates coefficients in a set of linear relationships in which the functional relationships are described by parameter estimates that show the magnitude, as well as the direction of effect the independent variables have on the dependent variable. It allows the researcher to explicitly accommodate measurement errors and incorporate abstract and unobservable constructs [62]. 


\section{$4 \quad$ Results}

\subsection{Measurement model}

Before testing the hypothesised relationships with SEM, the measurement model was tested for reliability and validity. Internal consistency reliability of the constructs was established by Cronbach's Alpha and composite reliability. Convergent validity was established by the factor and cross loadings and average variance extracted (AVE). As a rule of thumb, values above 0.6 for Cronbach's Alpha [63], 0.7 for composite reliability, 0.5 for AVE [61], and 0.5 for factor loadings [64] indicate a reliable and valid model. The Cronbach's Alpha values, composite reliability and AVE are presented in Table 4.

Table 4. Construct reliability and validity

\begin{tabular}{|l|c|c|c|}
\hline & Cronbach's Alpha & Composite Reliability & Average Variance Extracted (AVE) \\
\hline ACC & 0.514 & 0.764 & 0.633 \\
\hline ANX & 0.881 & 0.927 & 0.809 \\
\hline ATT & 0.923 & 0.951 & 0.866 \\
\hline BI & 0.951 & 0.969 & 0.912 \\
\hline ENJOY & 0.912 & 0.945 & 0.851 \\
\hline EXP & 0.644 & 0.849 & 0.737 \\
\hline JR & 0.891 & 0.932 & 0.821 \\
\hline PEOU & 0.921 & 0.940 & 0.759 \\
\hline PU & 0.895 & 0.922 & 0.704 \\
\hline SE & 0.937 & 0.960 & 0.888 \\
\hline SN & 0.775 & 0.869 & 0.690 \\
\hline TS & 0.938 & 0.970 & 0.942 \\
\hline USE & 0.701 & 0.860 & 0.755 \\
\hline
\end{tabular}

Whilst all study constructs met the minimum Cronbach's Alpha value of 0.6, system accessibility had a value of less than 0.6. Taber [65] recommended that constructs with low Cronbach's Alpha values be tested against other measures as Cronbach's alpha looks at similarity within questions and is dependent on the number of items. Because the composite reliability was above the recommended 0.7 value, the construct was considered for Confirmatory Factor Analysis (CFA). All other constructs satisfied the minimum requirements for internal consistency reliability by having Cronbach's Alpha above 0.6 and composite reliability above 0.7 .

AVE values were above 0.5 for all constructs, which confirm convergent validity. To further prove convergent validity, the factor loadings for all items used for analysis for each construct were above the generally agreed 0.5 minimum.

The afore-discussed quality measurements show evidence of the adequacy of the constructs' measures. The hypothesised model was therefore, supported by the sample. The goodness of fit criteria for the model was not reported as it is not considered to confirm appropriateness of methods in PLS-SEM analysis. PLS-SEM is confirmed with reliability and validity metrics only [66]. After confirming the adequacy of the 
measurement model, the structural equation modelling was performed to evaluate the relationships between latent variables.

\subsection{Structural model}

SmartPLS's Bootstrapping Path analysis was used to test the model hypothesised before. The results of the tests are presented in Table 5, including the conclusion on whether the hypotheses were supported or not.

Table 5. Bootstrap results

\begin{tabular}{|c|l|c|c|c|l|}
\hline Hypothesis & \multicolumn{1}{|c|}{ Hypothesis } & Path coefficient ( $\beta)$ & T-Statistic & P-Value & \multicolumn{1}{|c|}{ Result } \\
\hline 1 & SN -> PEOU & 0.027 & 0.289 & 0.773 & Not supported \\
\hline 2 & EXP -> PEOU & 0.032 & 0.308 & 0.758 & Not supported \\
\hline 3 & SE -> PEOU & 0.444 & 4.489 & 0.000 & Supported \\
\hline 4 & ENJOY -> PEOU & 0.289 & 2.652 & 0.008 & Supported \\
\hline 5 & ANX -> PEOU & -0.161 & 2.578 & 0.010 & Supported \\
\hline 6 & ACC -> PEOU & 0.063 & 0.842 & 0.400 & Not supported \\
\hline 7 & TS -> PEOU & 0.121 & 1.770 & 0.077 & Not supported \\
\hline 8 & SN -> PU & 0.016 & 0.203 & 0.839 & Not supported \\
\hline 9 & EXP -> PU & 0.159 & 1.635 & 0.103 & Not supported \\
\hline 10 & SE -> PU & -0.010 & 0.115 & 0.909 & Not supported \\
\hline 11 & ENJOY -> PU & 0.080 & 0.591 & 0.555 & Not supported \\
\hline 12 & PEOU -> PU & 0.258 & 2.083 & 0.038 & Supported \\
\hline 13 & JR -> PU & 0.435 & 3.684 & 0.000 & Supported \\
\hline 14 & PEOU -> ATT & 0.126 & 1.110 & 0.268 & Not supported \\
\hline 15 & PU -> ATT & 0.710 & 7.403 & 0.000 & Supported \\
\hline 16 & PEOU -> BI & 0.023 & 0.205 & 0.837 & Not supported \\
\hline 17 & PU -> BI & 0.382 & 2.705 & 0.007 & Supported \\
\hline 18 & SN -> BI & 0.295 & 4.229 & 0.000 & Supported \\
\hline 19 & ATT -> BI & 0.294 & 1.817 & 0.070 & Not supported \\
\hline 20 & BI -> USE & 0.410 & 6.203 & 0.000 & Supported \\
\hline
\end{tabular}

The strength of relationships tested is shown by the path coefficients and p-value [30]. The sign on the path coefficient indicates the type of relationship between variables which would either be positive or negative [61]. The t-statistic and p-values are normally used to identify statistically significant relationships between latent variables. A statistically significant relationship between variables is indicated by a p-value below 0.05 [61].

Results presented in Table 5 show that perceived ease of use for the sample was positively influenced by system self-efficacy and system enjoyment and negatively influenced by system anxiety whilst perceived usefulness was positively influenced by job relevance and perceived ease of use. Only perceived usefulness had a significant positive influence on attitude. Behavioural intention was positively influenced by perceived usefulness and subjective norm and in turn, positively influenced use behaviour. 


\section{$5 \quad$ Discussion of Findings}

Whilst mixed results were found in comparison to the theories used for the paper, the discussion will only focus on statistically significant relationships between variables. There will be no further discussion on statistically insignificant relationships. SEM results show that PEOU was significantly influenced by system self-efficacy, perceived enjoyment and system anxiety. Self-efficacy and enjoyment had positive influence whilst anxiety had a negative influence as generally agreed in theory. The strongest influence was exerted by self-efficacy $(\beta=0.444)$. This finding is consistent with findings of several prior studies on effect of self-efficacy [44], [67], perceived enjoyment [33], [68] and anxiety [49] on perceived ease of use.

From the conceptual framework, only job relevance and perceived ease of use were found to have statistically significant influence on perceived usefulness, with job relevance having the strongest effect $(\beta=0.435)$. This implies that a system that fits the job requirements and lecturers' work style has higher chances of being perceived as useful. If an LMS assists users in achieving their goal in a philosophy they believe in, then it will be utilised. The findings on effect of PEOU and job relevance on PU are corroborated by a number of studies [9], [42], [44], [47]-[50].

Perceived usefulness was found to have a statistically significant influence on attitude to use LMS $(\beta=0.710)$. The beta coefficient between PU and ATT $(\beta=$ 0.710 ) implies a very strong influence exerted by perceived usefulness on attitude. Of all the relationships hypothesised, PU and ATT had the strongest one, implying that PU is the primary determinant of attitude towards use of Blackboard LMS. The influence of PU on ATT was confirmed by [36], [42], [48].

Of the variables hypothesised to influence $\mathrm{BI}$, only $\mathrm{PU}(\beta=0.382)$ and $\mathrm{SN}(\beta=$ 0.295 ) were found to have a statistically significant positive influence on BI. The beta coefficients, however, show relatively weak relationships. The findings on influence of PU and SN on BI are in line with findings from several studies such as [57], [69], [70].

As expected, a positive behavioural intention led to actual use of technology. The results of proposed relationship in the study shows that BI had a statistically significant influence on actual use of Blackboard, a relationship that was relatively strong, with a beta coefficient of 0.410 . It can therefore be deduced that lecturers who intent to use Blackboard are most likely to end up using it. This finding is in sync with most technology acceptance models and is supported by findings from several empirical studies [9], [34], [55]. Radovan and Kristl [69] claim that users who favour use of LMS use it more frequently.

Although the findings of the study find support in several prior studies, there are also many other studies which found contrasting results. The major contrasting outcome is between the current study and factors affecting PU identified in GETAMEL. None of the factors was found to have a significant effect. Possible reasons for such discrepancies include the difference in the times when the studies were carried out, the unit of study and the place where the study was carried out. There is a four-year difference in the timing of studies and with the rate at which technology is changing, factors such as experience, self-efficacy and anxiety may look different. Most of the 
studies that were included in the meta-analysis that resulted in GETAMEL obtained data from university students. The characteristics of students and lecturers, due to age and experience, may be different. Whilst lecturers may be experienced, they might not enjoy technology as much as students, who are considered to be digital natives. Lastly, most studies that resulted in GETAMEL were carried out in the Asian countries with very few in Africa. This argument is confirmed by [12], [13]. Generation of contrasting results is, however, is not an uncommon feature. Several studies carried out to assess technology acceptance resulted in contrasting findings, possibly due to situational differences as argued by [34]. Situational differences could mean that differences in beliefs may affect the perceptions of different people on technology adoption.

Whilst a number of predicted relationships were not confirmed by the results, the argument that perceived usefulness is key to adoption and use of technology was supported. Of the extensions to GETAMEL, job relevance and subjective norm appeared to add explanatory power to the model. Job relevance was, in fact, the only external factor to influence PU, no other external factor established in GETAMEL had a significant effect. Subjective norm had an impact on the behavioural intention to use Blackboard.

\section{Conclusion}

The study determined the antecedents for LMS adoption and use. The findings revealed that LMS use is influenced by behavioural intention which is in turn, influenced by subjective norm and perceived usefulness. Perceived usefulness is influenced by job relevance and perceived ease of use whilst perceived usefulness is influenced by self-efficacy, enjoyment and anxiety. In its efforts to improve adoption and use of LMS, the selected HEI should consider actions that improve self-efficacy, enjoyment and job relevance whilst reducing anxiety among lecturers. The results show that GETAMEL may not be the best model to measure adoption and acceptance of technology by lecturers, as shown by the number of external factors that were found to be insignificant. A different model might need to be developed which considers the characteristics of lecturers.

Although the study was conducted on a historically disadvantaged institution, situated in rural South Africa and faced with numerous infrastructural challenges, the results were similar to several prior studies available. It does seem to show that the factors affecting the technology adoption are generally common and somehow result in related findings. The results could imply that, though HEIs are at different stages of development, in general when it comes to technology adoption, there are similarities. It can be concluded that the selected HEI community should understand that being an HDI should not have a huge impact on the adoption and use of technology.

The study has important implications for administrators in universities, especially those responsible for promoting learning experiences of students. These implications affect teaching and learning policies, financial budget and online teaching and learning awareness strategies. The management of the selected HEI should focus on im- 
proving technical support which would improve self-efficacy and enjoyment and reduce anxiety of lecturers towards LMS use. Prior to adoption of a LMS, HEIs should consult lecturers and tailor-make the system for it to fit the context of the lecturers. Aligning the LMS with the teaching requirements of lecturers will likely improve the acceptance and use of the LMS. HEIs should also adjust and develop LMS adoption models that bring about the cost benefit analysis led by management. The selected HEI can also improve adoption of LMS by rewarding adopters and giving small incentives. Having LMS champions and brand ambassadors is also proposed for each academic faculty. The location, status and level of development at the selected HEI should not be a limiting factor to adoption and utilisation of an LMS.

In reading the paper, it is critical to note the following limitations: (1) the model used was originally developed for acceptance of a new technology. The model, does however, give possible antecedents to LMS use; (2) the study focussed on people who are already users of LMS and their views may be completely different from those not using the system; (3) users without a WhatsApp were excluded from partaking in the survey thus, reducing the representativeness of the sample; (4) data was collected during the Covid-19 pandemic, which may have influenced perceptions of respondents, with the belief that teaching and learning may have to be moved completely online; and (5) the data was collected at a time when the institution was on lockdown, so only those with access to data/internet were able to participate.

Future studies should consider assessing the extent of Blackboard LMS use. Literature shows that most lecturers use LMSs as repositories and a communication tool. It would also add value to investigate antecedents of system self-efficacy, system anxiety and perceived enjoyment as these factors influence perceived ease of use which in turn, influences perceived usefulness.

\section{$7 \quad$ References}

[1] J. Uziak, M. T. Oladiran, E. Lorencowicz, and K. Becker, "Students' and instructor's perspective on the use of blackboard platform for delivering an engineering course," Electron. J. e-Learning, vol. 16, no. 1, pp. 1-15, 2018.

[2] Z. Hussein, "Leading to Intention: The Role of Attitude in Relation to Technology Acceptance Model in E-Learning," Procedia Comput. Sci., vol. 105, no. December 2016, pp. 159-164, 2017. https://doi.org/10.1016/j.procs.2017.01.196

[3] M. Kalogiannakis and S. Papadakis, "An evaluation of Greek educational Android apps for preschoolers," in The Proceedings of the 12th Conference of the European Science Education Research Association (ESERA), Research, Practice and Collaboration in Science EducationDublin City University and the University of Limerick, Dublin, Ireland, 2017.

[4] M. Kalogiannakis and S. Papadakis, "A proposal for teaching ScratchJr programming environment in preservice Kindergarten teachers," in the 12th Conference of the European Science Education Research Association (ESERA), Research, Practice and Collaboration in Science Education, 2017. [Online]. Available: https://www.researchgate.net/publication/ 320546761 [Accessed July 22, 2020].

[5] W. W. Goh, J. L. Hong, and W. Gunawan, "Exploring Lecturers' Perceptions of Learning Management System: An Empirical Study Based on TAM," Int. J. Eng. Pedagog., vol. 4, no. 3, p. 48, 2014. https://doi.org/10.3991/ijep.v4i3.3497 
[6] S. Chanjaradwichai, J. Na-Songkhla, and T. Chiasiriphan, "A trackable augmented learning media system for a higher education level," Int. J. Emerg. Technol. Learn., vol. 14, no. 13, pp. 129-144, 2019. https://doi.org/10.3991/ijet.v14i13.10177

[7] S. Papadakis, M. Kalogiannakis, E. Sifaki, and N. Vidakis, "Access Moodle Using Smart Mobile Phones. A Case Study in a Greek University," in Interactivity, Game Creation, Design, Learning, and Innovation. ArtsIT 2017, DLI 2017. Lecture Notes of the Institute for Computer Sciences, Social Informatics and Telecommunications Engineering., 229th ed., A. Brooks, E. Brooks, and N. Vidakis, Eds. Springer, Cham, 2018, pp. 376-385. https:// doi.org/10.1007/978-3-319-76908-0_36

[8] M. Zabolotniaia, Z. Cheng, E. Dorozhkin, and A. Lyzhin, "Use of the LMS Moodle for an Effective Implementation of an Innovative Policy in Higher Educational Institutions," iJET, vol. 15, no. 13, 2020. https://doi.org/10.3991/ijet.v15i13.14945

[9] N. Fathema, D. Shannon, and M. Ross, "Expanding the Technology Acceptance Model (TAM) to Examine Faculty Use of Learning Management Systems (LMSs) In Higher Education Institutions.," MERLOT J. Online Learn. Teach., vol. 11, no. 2, pp. 210-232, 2015.

[10] L. Mukhametshin and L. Salekhova, "Using the LMS Moodle system in the modern educational process," Philol. Cult., vol. 2, no. 56, pp. 274-279, 2019.

[11] B. A. Al-Alak and I. A. M. Alnawas, "Measuring the acceptance and adoption of elearning by academic staff," Knowl. Manag. E-Learning, vol. 3, no. 2, pp. 201-221, 2011. https://doi.org/10.34105/j.kmel.2011.03.016

[12] R. Baki, B. Birgoren, and A. Aktepe, "A meta-analysis of factors affecting perceived usefulness and perceived ease of use in the adoption of E-Learning systems," Turkish Online J. Distance Educ., vol. 19, no. 4, pp. 4-42, 2018. https://doi.org/10.17718/tojde.471649

[13] A. Granić and N. Marangunić, "Technology acceptance model in educational context: A systematic literature review,” Br. J. Educ. Technol., vol. 50, no. 5, pp. 2572-2593, 2019. https://doi.org/10.1111/bjet.12864

[14] J. Chipps, J. Kerr, P. Brysiewicz, and F. Walters, “A survey of University students' perceptions of learning management systems in a low-resource setting using a technology acceptance model," CIN Comput. Inform. Nurs., vol. 33, no. 2, pp. 71-77, 2015. https://doi. org/10.1097/cin.0000000000000123

[15] DHET, "Call for comments on the draft Social Inclusion Policy Framework for Public Post-School Education \& Training Institutions," Pretoria, 2014. [Online]. Available: http://www.gpwonline.co.za/Gazettes/Gazettes/37928_21-8_HighEduTrain.pdf [Accessed July 12, 2020].

[16] DHET, “Annual Report 2017/18," Pretoria, 2018. [Online]. Available: https://national government.co.za/entity_annual/1623/2018-council-on-higher-education-(che)-annual-rep ort.pdf [Accessed July 12, 2020].

[17] P. N. Nyoni, "Pedagogy and Agency in Postgraduate Student Supervision in a Rural South African University," in Postgraduate Research Engagement in Low Resource Settings (pp. 296-316)., D. Atibuni, Ed. IGI Global, 2020, pp. 296-316. https://doi.org/10.4018/978-17998-0264-8.ch015

[18] M. E. Muuro, W. P. Wagacha, R. Oboko, and J. Kihoro, "Students' Perceived Challenges in an Online Collaborative Learning Environment: A Case of Higher Learning Institutions in Nairobi, Kenya," Int. Rev. Res. Open Distance Learn., vol. 15, no. 6, pp. 132-161, 2014. https://doi.org/10.19173/irrodl.v15i6.1768

[19] E. Coleman and S. Mtshazi, "Factors affecting the use and non-use of Learning Management Systems (LMS) by academic staff," South African Comput. J., vol. 29, no. 3, pp. 3163, 2017. https://doi.org/10.18489/sacj.v29i3.459 
[20] D. Borboa, M. Joseph, D. Spake, and A. Yazdanparast, "Perceptions and Use of Learning Management System Tools and Other Technologies in Higher Education: A Preliminary Analysis.," J. Learn. High. Educ., vol. 10, no. 2, pp. 17-23, 2014.

[21] J. K. M. Ali, "Blackboard as a Motivator for Saudi EFL Students: A Psycholinguistic Study,” Int. J. English Linguist., vol. 7, no. 5, p. 144, 2017. https://doi.org/10.5539/ijel.v7 $\underline{\mathrm{n} 5 \mathrm{p} 144}$

[22] S. Liaw, "Investigating students' perceived satisfaction, behavioral intention, and effectiveness of e-learning; A case study of the Blackboard system," Comput. Educ., vol. 51, no. 2, pp. 864-873, 2008. https://doi.org/10.1016/j.compedu.2007.09.005

[23] C. Meier, "Enhancing intercultural understanding using e-learning strategies," South African J. Educ., vol. 27, no. 4, pp. 655-672, 2007.

[24] E. Bagarukayo and B. Kalema, "Evaluation of elearning usage in South African universities: A critical review," Int. J. Educ. Dev. Using Inf. Commun. Technol., vol. 11, no. 2, pp. 168-183, 2015.

[25] M. Letseka, M. M. Letseka, and V. Pitsoe, "The Challenges of E-learning in South Africa," in Trends in E-learning, IntechOpen, 2018. https://doi.org/10.5772/intechopen.74843

[26] W. Mlitwa and J. W. G. D. van Belle, "Mediators for lecturer perspectives on learning management systems at universities in the Western Cape, South Africa," in Pacific Asia Conference on Information Systems (PACIS), 2011.

[27] DHET, "Draft Policy Framework for the Provision of Open Learning and Distance Education in South African Post-School Education and Training," Pretoria, 2017. [Online]. Available: https://static.pmg.org.za/170407openlearningframework-postschooleduc.pdf [Accessed July 12, 2020].

[28] H. Lucas, "Technology and the Failure of the University," Commun. ACM, vol. 61, no. 1, 2018.

[29] F. D. Davis, R. P. Bagozzi, and P. R. Warshaw, "User Acceptance of Computer Technology: A Comparison of Two Theoretical Models," Manage. Sci., vol. 35, no. 8, pp. $982-$ 1003, 1989. https://doi.org/10.1287/mnsc.35.8.982

[30] F. Abdullah and R. Ward, "Developing a General Extended Technology Acceptance Model for E-Learning (GETAMEL) by analysing commonly used external factors," Comput. Human Behav., vol. 56, pp. 238-256, Mar. 2016. https://doi.org/10.1016/J.CHB.2015.11. $\underline{036}$

[31] A. Kemp, E. Palmer, and P. Strelan, "A taxonomy of factors affecting attitudes towards educational technologies for use with technology acceptance models," Br. J. Educ. Technol., vol. 50, no. 5, pp. 2394-2413, 2019. https://doi.org/10.1111/bjet.12833

[32] O. O. Durodolu, "Technology Acceptance Model as a predictor of using information system 'to acquire information literacy skills," Libr. Philos. Pract., vol. 1450, 2016.

[33] C. Ching-Ter, J. Hajiyev, and C. R. Su, "Examining the students' behavioral intention to use e-learning in Azerbaijan? The General Extended Technology Acceptance Model for Elearning approach,” Comput. Educ., vol. 111, pp. 128-143, 2017. https://doi.org/10.1016/j. compedu.2017.04.010

[34] T. Doleck, P. Bazelais, and D. J. Lemay, "Is a general extended technology acceptance model for e- learning generalizable?” Knowl. Manag. Int. E-learning, vol. 10, no. 2, pp. 133-147, 2018.

[35] J. Hajiyev, “Assessing Students' Attitude and Intention to Use M- learning in Higher Education," J. Contemp. Educ. Res., vol. 2, no. 2, pp. 17-25, 2018.

[36] A. Revythi and N. Tselios, "Extension of technology acceptance model by using system usability scale to assess behavioural intention to use e-learning," Educ. Inf. Technol., vol. 24, no. 4, pp. 2341-2355, 2019. https://doi.org/10.1007/s10639-019-09869-4 
[37] V. Venkatesh and F. D. Davis, "A Theoretical Extension of the Technology Acceptance Model: Four Longitudinal Field Studies,” Manage. Sci., vol. 46, no. 2, pp. 186-204, 2000.

[38] V. Venkatesh and H. Bala, "Technology acceptance model 3 and a research agenda on interventions,” Decis. Sci., vol. 39, no. 2, pp. 273-315, 2008. https://doi.org/10.1111/j.15405915.2008.00192.x

[39] T. F. I. Chan, M. Borja, B. Welch, and M. E. Batiuk, "Predicting the probability for faculty adopting an audience response system in higher education," J. Inf. Technol. Educ. Res., vol. 15 , no. 2016, pp. 395-407, 2016.

[40] V. Venkatesh, M. G. Morris, G. B. Davis, and F. D. Davis, "User Acceptance of Information Technology: Toward a Unified View,” MIS Q., vol. 27, no. 3, pp. 425-478, 2003.

[41] B. Eneizan, A. A. N. Mostafa, and A. S. Alabboodi, "Effect of Technical Support and Trust on the Adoption of Electronic Human Resource Management: Evidence from Developing Countries,” Int. J. Appl. Res., vol. 4, no. 7, pp. 31-40, 2018.

[42] E. Ibili, D. Resnyansky, and M. Billinghurst, "Applying the technology acceptance model to understand maths teachers' perceptions towards an augmented reality tutoring system," Educ. Inf. Technol., vol. 24, pp. 2653-2675, 2019.

[43] F. A. Kimathi and Y. Zhang, "Exploring the General Extended Technology Acceptance Model for e-Learning Approach on Student's Usage Intention on e-Learning System in University of Dar es Salaam," Creat. Educ., vol. 10, pp. 208-223, 2019. https://doi.org/10. 4236/ce.2019.101017

[44] A. Hanif, A. F. Siddiqi, and Z. Jalil, "Are computer experience and anxiety irrelevant? Towards a simple model for adoption of e-learning systems," Int. J. Eng. Pedagog., vol. 9, no. 5, pp. 112-125, 2019. https://doi.org/10.3991/ijep.v9i5.11488

[45] F. Huang, T. Teo, and R. Scherer, "Investigating the antecedents of university students' perceived ease of using the Internet for learning," Interact. Learn. Environ., pp. 1-17, 2020. https://doi.org/10.1080/10494820.2019.1710540

[46] A. Gunasinghe, J. A. Hamid, A. Khatibi, and S. M. F. Azam, "Does anxiety impede VLE adoption intentions of State University lecturers? - A study based on Modified UTAUT Framework," Eur. J. Soc. Sci. Stud., vol. 4, no. 4, pp. 46-71, 2019. https://doi.org/10.5281/ zenodo.3358154

[47] F. C. Duygu and O. Sevgi, “A model for instructors' adoption of learning management systems: Empirical Validation in higher education context," Turkish Online J. Educ. Technol., vol. 12, no. 2, pp. 13-25, 2013.

[48] V. Z. Vanduhe, M. Nat, and H. F. Hasan, "Continuance Intentions to Use Gamification for Training in Higher Education: Integrating the Technology Acceptance Model (TAM), Social Motivation, and Task Technology Fit (TTF)," IEEE Access, vol. 8, pp. 21473-21484, 2020.

[49] S. S. Al-Gahtani, "Empirical investigation of e-learning acceptance and assimilation: A structural equation model," Appl. Comput. Informatics, vol. 12, no. 1, pp. 27-50, 2016. https://doi.org/10.1016/j.aci.2014.09.001

[50] S. Alharbi and S. Drew, "Using the Technology Acceptance Model in Understanding Academics' Behavioural Intention to Use Learning Management Systems," Int. J. Adv. Comput. Sci. Appl., vol. 5, no. 1, pp. 143-155, 2014. https://doi.org/10.14569/ijacsa.2014.0501 $\underline{20}$

[51] K. I. Adenuga, V. W. Mbarika, and Z. O. Omogbadegun, “Technical Support: Towards Mitigating Effects of Computer Anxiety on Acceptance of E-Assessment Amongst University Students in Sub Saharan African Countries," in International Working Conference on Transfer and Diffusion of IT, 2019, pp. 48-72. https://doi.org/10.1007/978-3-030$\underline{20671-0 \_5}$ 
[52] S. Freitas, J. B. Ferreira, R. A. Garcia, and R. Kurtz, "The Effect of Interactivity and Technical Support in the use Intention of an E-learning System," Rev. Ciências da Adm., vol. 19, no. 47, pp. 45-56, 2017.

[53] D. Martinho, E. Santos, M. A. Miguel, and D. Cordeiro, "Factors that Influence the Adoption of Postgraduate Online Courses,” Int. J. Emerg. Technol. Learn., vol. 13, no. 12, pp. 123-141, 2018.

[54] Y. K. Dwivedi, N. P. Rana, A. Jeyaraj, M. Clement, and M. D. Williams, "Re-examining the Unified Theory of Acceptance and Use of Technology (UTAUT): Towards a Revised Theoretical Model," Inf Syst Front, vol. 21, pp. 719-734, 2019. https://doi.org/10.1007/s10 796-017-9774-y

[55] E. E. Marandu, F. Makudza, and S. Ngwenya, "Predicting Students' Intention and Actual Use of E-Learning Using the Technology Acceptance Model: A Case from Zimbabwe," Int. J. Learn. Teach. Educ. Res., vol. 18, no. 6, pp. 110-127, 2019. https://doi.org/10.268 03/ijlter.18.6.7

[56] Q. Kharma, "Investigating Students 'Acceptance of Online Courses at Al-Ahliyya Amman University," Int. J. Adv. Comput. Sci. Appl., vol. 10, no. 7, pp. 202-208, 2019. https://doi.org/10.14569/IJACSA.2019.0100729

[57] C. A. M. Urquidi, S. M. P. Calabor, and A. C. Tamarit, "Virtual Learning Environments: Extending the Technology Acceptance Model," Rev. Electrónica Investig. Educ., vol. 21, pp. 1-12, 2019.

[58] S. S. Binyamin, M. J. Rutter, and S. Smith, "Extending the technology acceptance model to understand students' use of learning management systems in Saudi higher education," Int. J. Emerg. Technol. Learn., vol. 14, no. 3, pp. 4-21, 2019. https://doi.org/10.3991/ijet. $\underline{\mathrm{v} 14 \mathrm{i} 03.9732}$

[59] I. Arpaci, P. O. Durdu, and A. Mutlu, "The Role of Self-Efficacy and Perceived Enjoyment in Predicting Computer Engineering Students' Continuous Use Intention of Scratch," Int. J. E-Adoption, vol. 11, no. 2, pp. 1-12, 2019.

[60] C. M. Chao, "Factors determining the behavioural intention to use mobile learning: An application and extension of the UTAUT model," Front. Psychol., vol. 10, no. JULY, pp. 114, 2019.

[61] C. M. Ringle, S. Wende, and J. M. Becker, "SmartPLS 3." Boenningstedt: SmartPLS GmbH, 2015. [Online]. Available: http://www.smartpls.com [Accessed June 2, 2020].

[62] J. Hair, R. Andersen, R. Tatham, and W. Black, Multivariate Data Analysis. New Jersey: Prentice-Hall, 2006.

[63] S. Sarosa, "The Role of Brand Reputation and Perceived Enjoyment in Accepting Compulsory Device'ss Usage: Extending UTAUT," Procedia Comput. Sci., vol. 161, pp. 115-122, 2019. https://doi.org/10.1016/j.procs.2019.11.106

[64] J. F. Hair, W. C. Black, B. J. Babin, and R. E. Anderson, Multivariate Data Analysis. NJ: Prentice Hall, 2010.

[65] K. S. Taber, "The Use of Cronbach's Alpha when developing and reporting research instruments in Science Education,” Res Sci Educ, vol. 48, pp. 1273-1296, 2018.

[66] J. Hair, C. L. Hollingsworth, A. B. Randolph, and A. Y. L. Chong, "An updated and expanded assessment of PLS-SEM in information systems research," Ind. Manag. Data Syst., vol. 117, no. 3, pp. 442-458, 2017. https://doi.org/10.1108/IMDS-04-2016-0130

[67] S. R. Thakkar and H. D. Joshi, "Impact of Technology Availability and Self-Efficacy on E-learning Usage,” Int. J. Res. Appl. Sci. Eng. Technol., vol. 6, no. 4, pp. 2956-2960, 2018. https://doi.org/10.22214/ijraset.2018.4492

[68] F. Abdullah, R. Ward, and E. Ahmed, "Investigating the influence of the most commonly used external variables of TAM on students' Perceived Ease of Use (PEOU) and Perceived 
Usefulness (PU) of e-portfolios.” 2016. [Online]. Avaliable: https://core.ac.uk/download/ pdf/42582523.pdf [Accessed April 6, 2020].

[69] M. Radovan and N. Kristl, "Acceptance of Technology and its Impact on Teacher's Activities in Virtual Classroom: Integrating UTAUT and CoI into a Combined Model," TOJET Turkish Online J. Educ. Technol., vol. 16, no. 3, pp. 11-22, 2017.

[70] B. Sumak and A. Sorgo, "The acceptance and use of interactive whiteboards among teachers: Differences in UTAUT determinants between pre- and post-adopters," Comput. Human Behav., vol. 64, pp. 602-620, 2016. https://doi.org/10.1016/j.chb.2016.07.037

\section{Authors}

Obert Matarirano is a senior lecturer in the Department of Accounting and Finance at Walter Sisulu University, Buffalo City Campus, East London, South Africa. His research interests include innovative teaching approaches, small business performance, and sustainable business models.

Hlanganani Siqondile Sibanda is a lecturer in the Department of Economics and Finance at Walter Sisulu University, Queenstown, South Africa. Her research interests include teaching with technology and development economics.

Nobert Rangarirai Jere is a senior lecturer within the Department of Information Technology at Walter Sisulu University, Buffalo City Campus, East London, South Africa. His research interests include emerging technologies in education and ICTs for service delivery.

Manoj Panicker is a senior lecturer and Head of the Department of Accounting at Walter Sisulu University, Butterworth Campus. His research interests include financial sustainability and application of the balanced scorecard in universities.

Article submitted 2020-07-04. Resubmitted 2020-08-06. Final acceptance 2020-08-10. Final version published as submitted by the authors. 